\title{
СЕЛЕКЦИЯ НА УСИЛЕНИЕ ЭКОЛОГИЧЕСКОЙ ПЛАСТИЧНОСТИ ОЗИМОЙ ПШЕНИЦЫ - ОДНО ИЗ ВАЖНЕЙШИХ УСЛОВИЙ ПРИ СОЗДАНИИ ВЫСОКОПРОДУКТИВНЫХ СОРТОВ
}

\author{
А. И. Грабовец, М. А. Фоменко \\ Донской зональный научно-исследовательский институт сельского \\ хозяйства РАСХН, Россия
}

Разработаны и внедрены основы ведения селекции пшеницы мягкой озимой на Дону при нарастании аридности климата, обусловливающие создание высокопластичных сортов, устойчивых к засухе, низким температурам в зимний период, негативному действию притертых ледяных корок, возвратным майским заморозкам. Созданы сорта нового поколения Донна, Золушка, Донская лира, Миссия, Магия и др.

Пшеница, селекция, устойчивость, засуха, морозостойкость, ледяная корка, майский заморозок

Начиная с 1989 г. в Ростовской области усилилась тенденция нарастания засушливости климата. Это выразилось в росте среднегодовой температуры воздуха $\left(+2,3^{\circ} \mathrm{C}\right.$ за период 1989-2012 гг.), уменьшении суммы летних осадков, в увеличении количества случаев, когда при вегетации озимых отсутствие осадков на фоне высоких температур воздуха длилось до полутора-двух месяцев. С начала 21 века семь лет были засушливыми. Выявлена достоверная особенность перераспределения осадков на осенне -зимние месяцы.

Заметно изменился температурный режим в зимне-весенний период, что выражается в усилении размаха колебания температур воздуха (от -40 ${ }^{\circ} \mathrm{C}$ до продолжительных оттепелей, часто с притертыми ледяными корками). Для весны характерен участившийся возврат заморозков при вегетации озимых культур в апреле и мае.

Повысить адаптивность озимой пшеницы путем создания пластичных сортов - одно из важнейших условий стабильности ее урожаев по годам. Одним из радикальных путей решения этой проблемы является увеличение доступной генетической изменчивости признаков, обуславливающих адаптивность, усиление рекомбинационных процессов и изменение их канализированности при взаимодействии генов.

Более действенным методом, наряду с другими способами, следует

(C) А. И. Грабовец, М. А. Фоменко. 2013.

ISSN 0582-5075. Селекція і насінництво. 2013. Випуск 103. 
считать гибридизацию специально подобранных компонентов. В генофонде популяции под давлением лимитирующего стрессора (или нескольких из них) в процессе рекомбинации происходит взаимное приспособление взаимодействующих аллелей, обуславливающее у ряда генотипов формирование признаков и свойств с большей степенью их выраженности в сравнении с родителями, позволяющей успешно преодолевать негативы среды - трансгрессии $[1,2,3$ и др.]. Особенно ценны популяции с продолжительным формообразовательным процессом [4].

Материал и методика. Исследования выполняли в течение 19892012гг. в Донском НИИСХ. К этому времени уже определились основные параметры модели сорта [ 4]. Растения пшеницы должны выдерживать на узлу кущения - 18-19C мороза, длительное залегание притертой ледяной корки, действие возвратных весенних морозов, иметь высокий уровень жаро- засухоустойчивости на всех этапах летнего роста и развития.

Схема ведения селекции в основном общепринятая. Селекционный питомник закладывали необмолоченными колосьями специально сконструированной сажалкой. Это позволяло (помимо удешевления стоимости работ) включать в изучение на первом этапе достаточно большое число генотипов (до 45000), что очень важно при трансгрессивной селекции.

В качестве исходного материала при гибридизации использовали собственный селекционный материал, также сорта, созданные в других научно-исследовательских учреждениях России, ближнего и дальнего зарубежья. Выявление трансгрессивных форм проводили, используя методики В. С. Воскресенской и В. И. Шпоты [5], Ю. Б. коновалова и Т. И. Хупацария [6].

Результаты. Негативные условия при перезимовке являются одними из основных стрессоров, которые определяют урожай зерна. Устойчивость растений к низким температурам на узле кущения до сих пор, несмотря на потепление климата, не потеряла своей актуальности. Здесь, как и во многих других исследованиях [7,8 и др.], большая значимость при создании новых сортов придавалась более высокозимостойкому (В3) родителю. Причем при скрещивании по схеме В3 х В3 не удавалось получать формы, более зимостойкие, чем родители. Были выделены рекомбинанты на уровне лучшего родителя. По такому принципу были созданы сорта Арфа, Донэко, Золушка,. Северодонская 12 и др.

При построении комбинации по типу В3 родитель / среднезимостойкий (Сp3) и наоборот трансгрессии по зимостойкости у гетерогенных популяций появлялись, но с незначительной степенью. Например у комбинации Тарасовская 97 (B3) / Прима одесская (Cp3) зимостойкость у гибрида $\mathrm{F}_{1}$ приближалась к В3 родителю, в $\mathrm{F}_{2}$ наследовалась промежуточно. В $\mathrm{F}_{3}$ из 240 изучаемых семей выделили 12 трансгрессивных форм (5\% от общего изученного числа), в $\mathrm{F}_{5}$ их было отобрано $6,5 \%$. Одной из них было дано название Донна (включена в госреестр в 2012 г). Донна превышала более 
зимостойкую в комбинации мать Тарасовскую 97 ежегодно на 5-6 \% выживших растений. Аналогичную ситуацию наблюдали при скрещивании Примы одесской (Сp3) / 560/97 (В3). Итогом было создание более зимостойкого, чем родители, сорта Донская лира (госреестр 2011 г.).

Однако наибольший эффект при создании высокозимостойких форм был получен при гибридизации по схеме Сp3 / Сp3. У популяций при длительной рекомбинации и давлении стрессора выщеплялись рекомбинанты с трансгрессией, существенно превышавшие по ее степени Сp3 родителей по зимостойкости. Многие из них приближались к так называемому филогенетическому "потолку“. У первого сорта Северодонская при температуре $19^{\circ} \mathrm{C}$ на узле кущения сохранялось до $62 \%$ растений, у родителей Безостая $1-42 \%$, Мироновской 808- $52 \%$, у Тарасовской 97 соответственно $76 \%$, q $35 \%$ и $\curvearrowright 42 \%$, у Росинки тарасовской $-75 \%$, о $49 \%$ и $ぇ 50 \%$, у Губернатора Дона $-78 \%$, ф $36 \%$ и ठ $56 \%$ у Авесты - $77 \%$, ф $56 \%$ и ठ $67 \%$; и др. Использование Сp3 сортообразцов в качестве родительских компонентов было более эффективным еще и из-за их более высокого потенциала продуктивности, лучшей устойчивости к фитопатогенам, полеганию и др. Практически не получали трансгрессий при скрещивании слабозимостойких сортообразцов с В3 и Срз из-за ограничений на рекомбинацию.

Наряду с морозами довольно губительны в Ростовской области притертые ледяные корки (ПЛК). В 2003 г. гибель озимых здесь по этой причине составила 413 тыс. га. Исследования по этой проблеме начали с 1972 года. За прошедший период выявлена положительная корреляция между морозостойкостью генотипа и его устойчивостью к ПЛК толщиной 2-3 см $(0,78 \pm 0,13)$. Поэтому процесс создания генотипов, устойчивых к ПЛК, идет параллельно с селекцией на морозостойкость. Принципы остаются те же. При использовании в качестве матери менее устойчивой формы у гибридов $\mathrm{F}_{1}$ чаще отмечали гетерозис по устойчивости к ПЛК (чем у реципрокного варианта), однако степень его выраженности все же предопределялась уровнем устойчивости более адаптированного в комбинации сорта.

В новом тысячелетии довольно заметно проявил себя относительно новый по частоте проявления лимитирующий фактор - весенние заморозки. В 2000 г. в мае за неделю перед выколашиванием температура воздуха понизилась до $-10-11^{\circ} \mathrm{C}$ и держалась в течение девяти дней. Гибель озимых составляла сотни тысяч гектаров, особенно в Воронежской области. Такое же явление наблюдали в ряде последующих лет, в том числе и на Кубани.

Местом первичного повреждения растений заморозком является транспортная система клеточных мембран хлоропластов [9]. Наименее устойчивыми к заморозкам в растении пшеницы оказались верхние цветки в зачаточном колосе и стебель между первым и вторым междоузлием. Второе место на растении оказалось превалирующим и обусловливало постепенно происходившую гибель растений (вследствие нарастания интоксикации изза нарушения активного транспорта метаболитов). 
Исследования 2000-2003 гг. не подтвердили наличия корреляции между морозо-зимостойкостью и устойчивостью к майским заморозкам и выявили четкую комбинативную природу этого явления. Контроль устойчивости к заморозкам обуславливался иным комплексом генов (Грабовец А. И., Фоменко М. А., 2007, стр.239). При этом при проведении топкроссов было определено необычайно четкое доминирование источников устойчивости к заморозкам (сорта Престиж, Северодонецкая 12, Тарасовская 97, Августа, Северодонецкая юбилейная, 1629/91, Спартанка, Альбатрос одесский и др.). По многим комбинациям отмечали довольно широкий спектр рекомбинационной изменчивости: от практически полной устойчивости (2-5\% гибели) до значимого отмирания растений (более 40 \%). Процесс усиления устойчивости к заморозкам был еще более существенным при беккроссах с использованием этого же или другого донора. То есть гены устойчивости к заморозкам, в основном аккумулируются при перекомбинировании и передаются потомкам. Получивший широкое распространение сорт Губернатор Дона выделяется высокой устойчивостью к заморозкам Он был выделен из популяции Альбатрос одесский / Харьковская 82 // Украинка одесская. По этой популяции целый ряд рекомбинантов вообще практически не повреждался заморозками (784/99- $0 \%$, 912/99- $1 \%, 813 / 99-2,5 \%$ и др.).

Как уже отмечали выше, начиная с 2000., в семи случаях отмечали засуху. Поэтому селекция на жаро-засухоустойчивость с учетом подвижек в окружающей среде должна быть одним из основных направлений в исследованиях по озимой пшеницы. Они должны базироваться на скороспелости вновь создаваемых генотипов (раннее время цветения) и детерминированной высоте растений. В первом случае, в сравнении с позднеспелыми генотипами, экономится определенное количество почвенной влаги, столь необходимое для дальнейшего развития растения и колоса. Исследования выявили также перспективность работы со среднерослыми морфобиотипами растений. Это нужно для сохранения должной массы надземной части растений для депонирования метаболитов, определяющих вал зерна (путем отбора генотипов с более сильно выраженным продуктивным кущением). Коэффициент корреляции пары признаков надземная масса - урожайность зерна с $1 \mathrm{~m}^{2}$ за изучаемый период составляет $\mathrm{r}=0,89 \pm 0,07$.

Высота стебля также должна сочетаться с урожаем зерна через оптимизацию величины уборочного индекса (корреляция у пары уборочный индекс - масса зерна с растения за 22 года составляла 0,69 г).

Самым надежным показателем засухоустойчивости является эффективность использования сортом почвенной влаги. При этом огромное значение приобретает пространственная ориентация листьев. На Дону более приемлемым является горизонтальное расположение листа (интенсивность транспирации у растений на свету выше, чем в тени, соответственно 870920 и 380-510 мг/дм ${ }^{2}$ вв час). Это подтверждается данными по количеству 
влаги за вегетационный период, необходимому для синтеза 1 г сухого вещества. Весовым методом [10] было выявлено, что у стародавнего сорта Гостианум 237 транспирационный коэффициент составлял 660 г, у сорта 70-х годов XX века Северодонская - 575, у современного сорта Губернатор Дона -465. То есть соотношение надземная биомасса / использование воды у новых сортов ближе к показателю, при котором формируется больший урожай зерна. Это обуславливает несколько пониженную температуру верхнего яруса листьев, высокую устьичную проводимость. В ряде исследований показано (Р. А. Ричардс и др. 2007), что они связаны с лучшим развитием корневой системы, быстрым нарастанием массы в фитоценозе сорта.

В селекционной практике существует ряд методов, как прямых, так и косвенных, применяемых при отборах на засухоустойчивость. Метод засушников очень затратный и недостаточно объективный вследствие сильного влияния компенсационных связей на продуктивность растений. Определенную информацию можно получить: изучая водоудерживающую способность растений при воздушной засухе, принимая во внимание большую длину верхней части соломины между колосом и верхним узлом; длинный колеоптиле, быстрый темп нарастания массы в посеве, стабильность выполненности зерновок по годам; продолжительность жизнедеятельности верхних листьев, синхронность выколашивания. При засухах особенно важное значение имеет соотношение между Р и $\mathrm{N}$ при питании растений ( оптимум $\mathrm{P}: \mathrm{N}=1: 1,2)$. Часто повышенная соломистость стеблестоя и щуплость зерна вызвана "перекосом" по азоту.

Однако наиболее объективным критерием оценки засухоустойчивости была масса зерна. Поэтому в условиях дефицита влаги основными практическими критериями при проведении отборов были дата начала колошения и масса зерна с растения, с единицы площади, характер проявления трансгрессивной изменчивости по этим признакам.

В нашей программе исследования базируются на создании популяций с высокой гетерогенностью по изучаемым свойствам и признакам. Принципы определения нужных исходных форм для гибридизации в условиях Дона были изложены ранее [4 ]. За период 1967 -2012гг. было районировано или включено в Госреестр Российской Федерации 29 сортов озимой пшеницы. Преобладающая их часть - это трансгрессивные рекомбинанты.

Всего 13 сортов были выделены из популяций, созданных путем парных скрещиваний сортов (табл. 1). Следует отметить значимую роль использования местных форм с коадаптированными комплексами генов для усиления адаптивных свойств у новых генотипов. За счет аккумулирования экспрессии генов происходило усиление выраженности признака устойчивости к стрессору. Конечно, роль местных форм в качестве одного из основных направлений в селекции не следует сильно преувеличивать. Ибо практически все они в свое время были выделены из популяций, у которых исходными компонентами служили формы, отдаленные в эколого-географическом аспекте. 
Таблица 1

Родословные ряда сортов (Госреестр России и Украины)

\begin{tabular}{|l|l|}
\hline \multicolumn{1}{|c|}{ Сорт* $^{*}$ Комбинация скрещивания } \\
\hline Арфа & \multicolumn{1}{|c|}{ Северодонская 12 / Альбатрос одесский, УКР } \\
\hline Донна & Тарасовская 97 / Прима одесская, УКР. \\
\hline Миссия & Северодонецкая юбилейная / Зерноградка 9, РОС \\
\hline Тарасовская 70 & Северодонецкая юбилейная / Дон 95, РОС \\
\hline Росинка тарасовская. & Соратница, РОС / Донщина. РОС \\
\hline
\end{tabular}

Остальные 16 сортов были созданы на основе ступенчатой гибридизации различной сложности с использованием как инорайонных морфобиотипов, так и генотипов местного происхождения. При ступенчатой гибридизации на каждой “ступеньке" после рекомбинации выделяли константные формы с коадаптированными комплексами генов. Их скрещивали на следующей "ступеньке“ с другим сортом, и процесс повторялся, но уже с усилением выраженности селектируемых признаков. Часто у таких популяций продолжительность рекомбинационного процесса увеличивалась (табл. 2).

Таблица.2

Родословные ряда сортов озимых пшениц тарасовской селекции

\begin{tabular}{|l|l|}
\hline \multicolumn{1}{|c|}{ Сорт* } & \multicolumn{1}{|c|}{ Крмбинация скрещивания } \\
\hline $\begin{array}{l}\text { Губернатор } \\
\text { Дона }\end{array}$ & $\begin{array}{l}\text { Альбатрос од., УКР / Харьковская 82, УКР // Украинка } \\
\text { одесская., УКР. }\end{array}$ \\
\hline Агра & $\begin{array}{l}\text { Тарасовская 87 / 109786, БЛГ // Телец, БЛГ / Донская } \\
\text { интенсивная, РОС /// MВ 12, ВНГР / Донщина, РОС }\end{array}$ \\
\hline Доминанта & $\begin{array}{l}\text { (DZ 21, РУМ // 9372/78 / Астра, УКР /// Одесская 133, } \\
\text { УКР) /// Тарасовская 29 / Дрина, ЮГСл // Альбатрос } \\
\text { одеский ,УКР }\end{array}$ \\
\hline $\begin{array}{l}\text { Северодонецкая } \\
\text { юбилейная. }\end{array}$ & $\begin{array}{l}\text { Тар.29 / Дрина, ЮГСл // Краснодарск.57, РОС /// Аль- } \\
\text { батрос одесский, УКР }\end{array}$ \\
\hline Авеста & $\begin{array}{l}\text { Никония, УКР // Тарасовская 97 /// Телец БЛГ / Дон- } \\
\text { ская интенсивная. РОС }\end{array}$ \\
\hline Магия & $\begin{array}{l}\text { (DZ 21, РУМ // 9372/78 / Астра, УКР /// Одесская 133, } \\
\text { УКР) / Северодонецкая юбилейная }\end{array}$ \\
\hline
\end{tabular}

Примечание. УКР-Украина, РОС -Россия, БЛГ -Болгария, РУМ- Румыния, ЮГСл -Югославия, ВНГР -Венгрия. * Находящиеся в Госреестрах России и Украины.

В среднем за 1989-2011 гг. частота выщепления трансгрессивных генотипов у популяций по массе зерна с единицы площади в первые годы рекомбинационного процесса возрастала от $2,45 \%$ в $\mathrm{F}_{3}$ до $3,9 \%$ в $\mathrm{F}_{5}$. Затем по мере уменьшения экспрессии взаимодействующих генов показатель частоты уменьшался от $2,2 \%$ в $\mathrm{F}_{6}$ до $0,3 \%$ в $\mathrm{F}_{14}$. Причем это наблюдали как 
в засушливые годы (1993, 1995, 2009-2011 и др.), так и при достаточном количестве влаги (2004, 2006, 2008 гг. и др.). С 2000 г. подбор исходных компонентов при гибридизации осуществляли уже с целью получения популяций с продолжительной рекомбинацией, что положительно сказывалось на частоте проявления трансгрессий в старших поколениях.

Установленная закономерность увеличения частоты проявления трансгрессий по продуктивности в условиях засух от $\mathrm{F}_{3}$ к $\mathrm{F}_{5}-\mathrm{F}_{7}$ используется довольно интенсивно в настоящее время в селекционном процессе. Причем, это осуществляется путем повторных отборов в гетерогенных популяциях , чередующихся один за другим, что позволяет вносить "коррективы“ в коадаптацию аллелей под влиянием давления стрессоров (табл. 3).

Таблица 3

Частота и степень трансгрессии по урожайности с $1 \mathrm{~m}^{2}$ при повторных отбоpax в $\mathrm{F}_{3}-\mathrm{F}_{7}$, селекционный питомник, 2001-2007 гг.

\begin{tabular}{|c|c|c|c|c|c|}
\hline \multirow{2}{*}{$\begin{array}{c}\text { Поколе- } \\
\text { ние } \\
\text { отбора }\end{array}$} & \multirow{2}{*}{$\begin{array}{l}\text { Изучено } \\
\text { семей, } \\
\text { количе- } \\
\text { ство }\end{array}$} & \multirow{2}{*}{$\begin{array}{c}\text { Частота } \\
\text { трансгрес- } \\
\text { сии, \% }\end{array}$} & \multicolumn{2}{|c|}{$\begin{array}{c}\text { Степень трансгрессии, } \\
\%\end{array}$} & \multirow{2}{*}{$\begin{array}{l}\text { Выделен } \\
\text { сорт }\end{array}$} \\
\hline & & & $\begin{array}{l}\text { сред- } \\
\text { нее }\end{array}$ & $\begin{array}{c}\text { пределы } \\
\text { варьирования }\end{array}$ & \\
\hline \multicolumn{6}{|c|}{ Северодонецкая юбилейная / Дон 95} \\
\hline $\mathrm{F}_{3}$ & 396 & 2,5 & 42 & $13-83$ & \\
\hline $\mathrm{F}_{5}$ & 288 & $\mathbf{5 , 0}$ & 17 & $2-44$ & Тарасовская 70* \\
\hline \multicolumn{6}{|c|}{$\begin{array}{c}\text { 1099/97 DZ -21, Румыния // 9372/78 / Астра /// Одесская } 133 \\
\text { ////Северодонецкая юбилейная }\end{array}$} \\
\hline $\mathrm{F}_{3}$ & 396 & 2,5 & 45 & $13-83$ & \\
\hline $\mathrm{F}_{5}$ & 300 & 5,7 & 33 & $4-67$ & Магия* \\
\hline \multicolumn{6}{|c|}{ Северодонецкая юбилейная / Зерноградка 9} \\
\hline $\mathrm{F}_{3}$ & 492 & 3,9 & 33 & $13-83$ & \\
\hline $\mathrm{F}_{4}$ & 324 & 0 & - & - & \\
\hline $\mathrm{F}_{5}$ & 426 & 6,0 & 23 & $8-52$ & Миссия* \\
\hline $\mathrm{F}_{6}$ & 600 & 4,0 & 22 & $8-42$ & Донэра \\
\hline $\mathrm{F}_{7}$ & 200 & 2,0 & 21 & $4-38$ & \\
\hline
\end{tabular}

Примечание. * Включены в Госреестр РФ.

Как показали исследования [4], характер проявления трансгрессий по продуктивности и длительность рекомбинации зависели во многих случаях от особенностей наследования признака масса зерна с растения (маркер). При проявлении гетерозиса в $\mathrm{F}_{1}$ по этому признаку примерно у 80 \% популяций можно было ожидать выщепление трансгрессивных форм. Во влажные годы эта закономерность уменьшалась, в засушливые годы - возрастала. Одновременно при засухах отмечается и много модификаций по продуктивности, которые впоследствии не наследуются.

Не менее результативны по выходу трансгрессивных рекомбинантов 
популяции с промежуточным наследованием маркерного признака в $\mathrm{F}_{1}-\mathrm{F}_{2}$. В разные годы появление таких морфобиотипов выявляли у 70-77 \% комбинаций. Единичные трансгрессии были установлены у комбинаций с наследованием массы зерна с растения по типу лучшего родителя. Приведенные закономерности проявления положительных трансгрессий базируются на неаллельном взаимодействии генов и выявляются у комбинаций с высокой комбинационной способностью.

Таким образом, на Дону отмечается усиление негативного воздействия зимне-весенних погодных аномалий и засух. Наиболее действенным инструментом в этих условиях является ступенчатая гибридизация, большие возможности по генетической изменчивости, поддающейся отбору, коадаптация аллелей при длительном действии различных лимитирующих стрессоров в процессе перекомбинирования генов;

В сложившихся условиях помимо создания более скороспелых сортов важно сохранить оптимальный вес надземной массы на единице площади. При засухах наиболее объективным показателем при отборах является масса зерна с единицы площади и с растения. Именно с этих позиций следует рассматривать все процессы подбора исходных компонентов, построения гетерогенных популяций, особенностей перекомбинирования, методологии выявления плюс трансгрессий по продуктивности.

На основе этих разработок созданы сорта нового поколения Донна, Золушка, Донская лира, Миссия, Магия, Тарасовская 70 и др.

\section{Список использованных источников}

1. Smith G. S. Transgressive segregation in spring wheat / G. S. Smith //Crop Sciences. -1966 . - № 6 .

2. Хейн Э. Д. Селекция пшеницы / Э. Д. Хейн, Д. С. Смит // Пшеница и ее улучшение. - М.: Колос, 1970.

3. Грабовец А. И. Основные принципы целенаправленного использования трансгрессивной изменчивости признаков при селекции озимой пшеницы / А. И. Грабовец // Селекция озимой пшеницы. Матер. научн.-практ. конф. "Научное наследие академика И.Г.Калиненко". - М.: РАСХН, 2001.

4. Грабовец А. И. Озимая пшеница / А. И. Грабовец, М. А. Фоменко. - Ростов-на-Дону: Юг, 2007.

5. Воскресенская Г. С. Трансгрессия признаков у гибридов Brassica и методика количественного учета этого явления / Г. С. Воскресенская, В. И. Шпота //ДАН СССР. - 1967. - № 7.

6. Коновалов Ю. Б. Выделение трансгрессивных форм из межсортовых гибридов мягкой яровой пшеницы / Ю. Б. Коновалов, Т. И. Хупацария // Известия Тимирязевской с.-х. академии. - 1976. - № 2.

7. Орлюк А. П. Некоторые генетические аспекты селекции озимой пшеницы на зимостойкость / А. П. Орлюк // Методы и приемы повышения зимостойкости зерновых культур. - М.: Колос, 1975. 
8. Булавка A. B. Морозоустойчивость гибридов от скрещивания сортов мягкой пшеницы, различающихся по данному признаку / А. В. Булавка // Тез. докладов V съезда ВОГИС. - М., 1987. - Т. IV. - Ч. I.

9 Палта Д. П. Свойства клеточных мембран в связи с повреждением при замерзании / Д. П. Палта, Х. П. Ли // Холодостойкость растений. - М.: Колос, 1983.

10. Гродзинский A. М. Краткий справочник по физиологии растений / А. М. Гродзинский, Д. М. Гродзинский. - Киев: Наукова думка, 1973. 